\title{
Disposition Effect and Mutual Fund Performance
}

\author{
Manuel Ammann, Alexander Ising and Stephan Kessler * \\ University of St. Gallen
}

May 2011

\begin{abstract}
This article finds strong evidence for the presence of the disposition effect among US mutual fund managers. The analysis can establish a link between the disposition effect and mutual fund characteristics as well as changes in the macroeconomic environment. Managers with a lower disposition effect are found to invest in larger equities with a higher trade volume, a higher past performance, lower idiosyncratic risk, and a higher risk-adjusted performance. However, fund characteristics and the economic environment can only explain a limited amount of the variation in the disposition effect across mutual funds. Using a new methodology to reduce the disposition effect exhibited by mutual fund investments, we find no increase in their profitability. Although statistically significant, the disposition effect has only a minor economic effect on fund performance.
\end{abstract}

Keywords: Disposition effect, mutual fund performance, behavioral finance

JEL Classifications: G11

\footnotetext{
*Manuel Ammann (manuel.ammann@unisg.ch) is professor of finance, at the Swiss Institute of Banking and Finance, University of St. Gallen, Switzerland, Alexander Ising (alexander.ising@gmail.com) is a fund analyst and portfolio manager at a Swiss bank, and Stephan Kessler (stephan.kessler@unisg.ch) is lecturer at the University of St. Gallen, Switzerland.
} 


\section{Introduction}

Investors are reluctant to realize their losses and hold losing stocks for a longer period of time than winning stocks. This observation is termed disposition effect and is studied extensively in previous research. The existing literature focuses on two aspects of the disposition effect. First, it is a behavioral irrationality which allows us to deepen our understanding of the psychological aspects of investment decisions. Second, the disposition effect might have a considerable impact on the performance of actively managed portfolios and could be an explanation for the profitability of momentum strategies. This article provides new insights into the presence of the disposition effect among US mutual fund managers, its systematic drivers, and the performance impact of the disposition effect.

An article by Shefrin and Statman (1985) is considered to be one of the seminal articles in the empirical analysis of the disposition effect. Using monthly data on mutual fund stocks from 19611981, Shefrin and Statman (1985) show that investors sell winners earlier than losers and term this finding "disposition effect". The authors generalize the choice under uncertainty of Kahneman and Tversky (1979) into a wider theoretical framework by introducing mental accounting, regret aversion, self-control, and tax considerations. A large range of academic work confirms the presence of the disposition effect in the trading decisions of investors, e.g., Barber and Odean (1999), Oehler, Heilmann, Lager, and Oberlander (2003), or Weber and Camerer (1998). Grinblatt and Keloharju (2001) study the Finnish stock market and find that the disposition effect as well as taxation sales prompt investors to sell stocks. The disposition effect is weakened by tax-loss selling activities. Odean (1998) analyzes the frequency at which winning and losing stocks are sold, finding evidence for the disposition effect in the trading records of 10,000 private accounts from 1987-1993. Locke and Mann (2005) find evidence for the disposition effect in the transactions of professional futures traders on the Chicago Mercantile Exchange. In their article the least successful traders have the longest holding period for losers while the traders who trade more frequently are more successful. Frino, Johnstone, and Zheng (2004) compare the disposition effect of futures traders who are onfloor (local) with off-floor (non-local) traders. They find the disposition effect for both groups, but local traders, who possess an informational advantage, show a stronger disposition effect. Krishnan and Booker (2002) analyze the disposition effect of investors who use analyst recommendations. Their experimental setting shows that analyst recommendations reduce the disposition effect for winning stocks but not for losing stocks. For a major Israeli brokerage house, Shapira and Venezia (2001) show that in 1994 not only private accounts are subject to the disposition effect, but also accounts managed by professionals. One result is that the effect is smaller for professional investors. 
An article by Dhar and Zhu (2002) investigates the disposition effect on an individual basis. Using trading records of a major discount brokerage house, they find that investors with more experience in trading and better access to financial market information show a smaller disposition effect. Frazzini (2006) uses data of mutual fund holdings to show an underreaction of stock prices to public news. This underreaction is influenced by the disposition effect of mutual fund managers with large positions in stocks. Brown, Philip, Chappel, Nick, Rosa, Ray, Walter, and Terry (2006) show that the disposition effect exists for different categories of Australian investors during the whole year except for June, which is the last month of the Australian fiscal year. Following an approach by Odean (1998), they come to the conclusion that the disposition effect is mitigated by selling activities for tax reasons 1 These results correspond to the findings of Da Silva Rosa, To, and Walter (2006) ${ }^{2}$ Grinblatt and Han (2005) develop a model of equilibrium asset prices showing that momentum is caused by the underreaction to firm specific news. They trace this momentum back to the disposition effect. Using data from the Shanghai Stock Exchange from 2001 to 2004, Shumway and $\mathrm{Wu}$ (2005) confirm the hypothesis that momentum is driven by the disposition effect. However, Barber, Lee, Liu, and Odean (2007) analyze the trades of different groups of investors on the Taiwan Stock Exchange from 1995 to 1999 and find evidence for the disposition effect but not for momentum. The authors argue that the existing disposition effect is not sufficient to generate momentum. Cici (2005) conducts research of the link between the disposition effect and mutual funds performance. He finds that mutual funds, on average, realize losses earlier than gains, contradicting Frazzini (2006) and our findings of the disposition effect within mutual funds, as well as other work in this area (compare, e.g., Odean (1998), Da Silva Rosa, To, and Walter (2006)).

Our contribution to the existing literature is to deliver a detailled analysis of the disposition effect among US mutual fund managers ${ }^{3}$ This analysis is supplemented by an investigation of the links between the disposition effect and the investment styles of mutual fund managers. Furthermore, we analyze the effect of fund characteristics (e.g., expense ratio and turnover) and the economic environment on the disposition effect exhibited by mutual fund managers. Another major contribution of this article is the analysis of the interaction between the disposition effect and the performance of mutual funds. To our knowledge, we are the first to explicitly analyze the impact of the timing of sales decisions on the disposition effect and the performance of mutual funds. The

\footnotetext{
${ }^{1}$ Odean (1998) shows that US investors realize tax loses in December, which is the end of the fiscal US year.

${ }^{2}$ Da Silva Rosa, To, and Walter (2006) use daily holding positions from September 2001 to September 2004 for all 4264 UK managed funds and find a disposition effect that is lower than the one reported by Odean (1998).

${ }^{3}$ The analysis of mutual funds is particulary interesting because they have low transaction costs, thereby reducing the noise level in the data and making the measurement of the disposition effect easier and more reliable (compare Shefrin and Statman (1985)).
} 
results of this article improve our understanding of behavioral patterns common to mutual fund managers and the performance impact of these patterns.

The remainder of this article is organized as follows. In the next section we describe our data set. Section 3 introduces the methodology used to calculate the disposition effect. In Section 4 we analyze the extend of the disposition effect in our dataset and its effect on investment decisions. The impact of the fund characteristics and the economic environment on the disposition effect among mutual fund managers is discussed in Section 5 . In Section 6 we study the link between fund performance and the disposition effect as well as the impact of the timing of sales on fund performance. Section 7 gives the conclusions.

\section{Data Description}

The database studied in this analysis is generated by merging the CRSP mutual fund database, the CRSP equity database, the Compustat database, and the Thomson Financial Mutual Funds database. The data includes 2,271 mutual funds between 1993 to 2005. Our merged database contains 33,627 single reported holding records.

One of the first combinations of the CRSP mutual fund database and the Thomson Financial Mutual Funds database (TFMF) is performed by Wermers (2000). We follow his approach, but extend it with information retrieved from the Compustat database. First, all mutual funds available in the CRSP mutual fund database are retrieved. From 1993 to 1999, data from CRSP is available on a yearly, afterwards on a quarterly basis. We delete mutual fund records without or with a reused ticker symbol ${ }^{4}$ to ensure the correct identification of the funds and the matching with other databases. Since this article focuses on mutual funds investing in equities, a fund is kept only if it invests at least $80 \% 5$ of its assets in equities for its whole recording period in CRSP. The CRSP database treats each share class of a mutual fund as a separate mutual fund. We identify the separate share classes issued on a single mutual fund and summarize them in one single record.

To merge the mutual fund characteristics in the CRSP database and the holdings information in the TFMF, the tickers from CRSP have to be mapped to the fund numbers from TFMF to link the fund characteristics. Unfortunately, such a mapping is only available for the time period from 1999 to 2005. For some mutual funds it is possible to extend this mapping to earlier dates. For

\footnotetext{
${ }^{4}$ However, mutual funds having a ticker for some but not for all records are kept.

${ }^{5}$ This number is subject to sensitivity tests, but the funds deleted are comparably insensitive to this threshold.
} 
other funds the mapping from 1993 to 1999 has to be performed manually. Funds which cannot be matched are deleted. The TFN database reports the Investment Objective Code (IOC) for each fund. Funds classified by the IOC as investing in international equities are deleted because of our concentration on North American stocks. Mutual funds investing in bonds, municipal bonds, balanced strategies, and metals are deleted because of our focus on equities. Furthermore, funds whose strategy is unclassified are deleted.

The next step is to characterize fund holdings by financial statistics. For each mutual fund not deleted, the TFMF database delivers its holdings information, i.e., the CUSIPs, the number of assets held, and the price for each holding, on a quarterly to yearly basis. Using the CUSIPs, the Compustat and CRSP merged monthly equity database is used to retrieve a number of accounting figures and trading statistics on each stock. Furthermore, we use daily data from CRSP to calculate three month stock return volatilities, mean returns, betas (with the S\&P500 as market index), and liquidity measures for all month ends in the sample period. Finally, the CRSP database of monthly prices is used to determine an average purchase price for each single stock issue held by a mutual fund 6 This average purchase price and the information on the time points of transactions are used to analyze the disposition effect. We add these accounting and capital market figures to the TFMF record of each stock in the sample. In a next step, the arithmetic average, the median, the standard deviation, and the value-weighted average of each of these measures are calculated for the holdings of each fund at every single recording date in the TFMF database. The result of this averaging is the "modified" TFMF database.

Finally, a full fund record is obtained by merging the results of the modified TFMF database with the information on the fund characteristics from the CRSP mutual fund database.

\section{Methodology}

To determine the disposition effect, the transactions of mutual funds are analyzed. We start by calculating the gains and losses for each mutual fund and then aggregate these numbers across the different mutual funds in the sample. The amount of shares bought or sold by a mutual fund are derived from changes in the total number of assets held. Some of the mutual funds in the sample hold shares before our dataset starts. Since we cannot determine purchase prices and dates for these shares, we only include the holdings whose purchasing quarter and price is known to us 7

\footnotetext{
${ }^{6}$ The price of the stock is taken at the reporting date. This corresponds to the procedure followed by Frazzini (2006).

${ }^{7}$ The average purchase price is calculated as the purchase price of the stock weighted by the amount of shares bought as in Odean (1998), Grinblatt and Keloharju (2001), and Da Silva Rosa, To, and Walter (2006).
} 
Purchasing time and price is used to determine a reference price for calculating gains and losses of mutual funds.

For the calculation of gains and losses at each reporting date, we compare the actual price of a share to its average purchase price. We classify a position as unrealized gain (paper gain) if the average share price is smaller than the actual share price and as an unrealized loss (paper loss) otherwise. If the actual price equals the average purchase price, the respective position is neither a paper gain nor a paper loss. If the change of the holding size of a specific stock is smaller than zero (i.e., shares are sold), we obtain a realized gain for positions with an actual share price greater than the average purchase price and a realized loss otherwise. All gains and losses are calculated on an amount of share basis and on a USD basis. Gains and losses on a USD basis are obtained by multiplying the amount of shares sold with the difference of actual share price minus average purchasing share price. The shares which are not sold in a given period are separated in positions which trade above and below their purchasing price, resulting in unrealized gains and losses, respectively. The unrealized gains (losses) are calculated as the differences between the purchasing price of a position and its price at the respective reporting date. For each mutual fund these figures are added up for all positions. Gains and losses on an amount of share basis are determined as the number of sales that are a realization of a profit or loss, respectively, where it does not matter how many shares are sold (compare Odean (1998) for further information). Equities which are not sold in a given period generate an unrealized gain (loss) if the present share price is above (below) the average purchase price, where all shares with the same CUSIP are counted as one. For example, if there are X unique CUSIPS with prices above the average purchasing price in the portfolio, they are counted as X unrealized gains. In the amount of shares approach it does not matter how many single shares of a CUSIP are held (causing an unrealized gain / loss) or traded (causing a realized gain / loss) by a mutual fund.

To test for the existence of the disposition effect we calculate the proportion of gains realized $(P G R)$ and the proportion of losses realized $(P L R)$ :

$$
\begin{aligned}
P G R & =\frac{\text { realized gains }}{\text { realized gains }+ \text { unrealized gains }} \\
P L R & =\frac{\text { realized losses }}{\text { realized losses }+ \text { unrealized losses }} .
\end{aligned}
$$

Since the disposition effect refers to the observation that investors tend to realize profits earlier than losses, the difference between $P G R$ and $P L R$ is a measure for the extent of the disposition effect (compare Odean (1998) for a detailled discussion). Thus, we define the disposition effect measure, $D E M$, as 


$$
D E M=P G R-P L R
$$

The larger the $D E M$ for a mutual fund, the stronger is the disposition effect exhibited by the respective fund manager.

\section{Extent of the Disposition Effect Among Mutual Fund Managers}

\subsection{Realized Profits of Mutual Funds}

The first step for the calculation of the disposition effect measure is the calculation of unrealized gains, unrealized losses, realized gains, and realized losses 8 This section starts with a short analysis of these figures as Section 6 studies the link between the disposition effect and mutual fund performance (i.e., profits of mutual funds). We analyze gains and losses for the whole sample (19932005) as well as for two subperiods (1993-1999 and 2000-2005) to obtain a deeper understanding of the profit dynamics.

Table 1: Realized gains and realized losses for the whole sample period and two subperiods in bn USD.

\begin{tabular}{lrrr}
\hline & $1993-2005$ & $1993-1999$ & $2000-2005$ \\
\hline Realized gains & 6,026 & 2,513 & 3,513 \\
Realized losses & $-3,267$ & $-1,016$ & $-2,252$ \\
Realized gains+realized losses & 2,759 & 1,497 & 1,262 \\
\hline
\end{tabular}

The table summarizes the realized gains, losses, and their sum across the whole sample period and two subperiods.

The amount of realized gains and losses across the whole sample period (1993-2005) is displayed in Table 1. During the whole observed time frame (1993-2005) the overall realized gain of the mutual funds in our sample is $\$ 2,759$ billions with an average gain per trade of $\$ 1.3$ millions (compare Table 1). If we only consider the period of 1993-1999, we measure a realized gain of $\$ 1,497$ billions, which is in line with the $\$ 1,261$ billions for $2000-2005$. However, the average gain

\footnotetext{
${ }^{8}$ By our procedure of calculating realized gains and losses we do not include possible gains or losses that result by shares bought before 1993 so that we will have a survivorship bias.
} 
per trade is much higher in the first period ( $\$ 3.2$ millions in the first period versus $\$ 0.8$ millions in the second).

Figure 1: Realized gains, realized losses, differences and the S\&P 500 from 1993-2005.

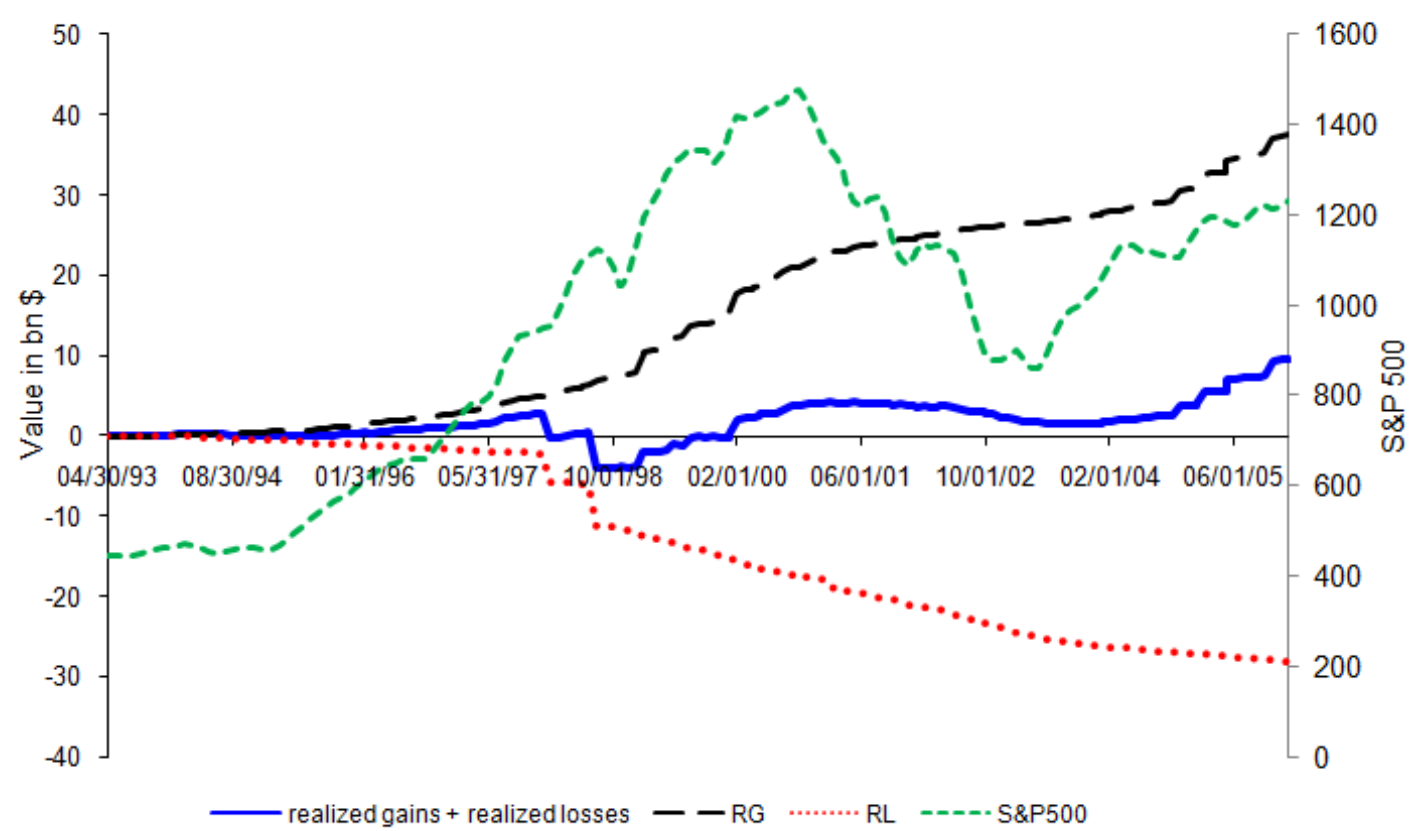

The figure shows the sum of the average realized gains, realized losses, and its difference for each reporting date from 1993 to 2005.

Figure 1 depicts the cumulative realized gains, realized losses, and realized gains plus realized losses over time. During the market downturn from 2000 to 2001 there is a considerable amount of realized gains. However, the cumulative realized gains grow slower than during the boom phase. Fund managers seem to get out of the market at this time, realizing what is left of their paper gains. The total realized losses increase (in absolute terms) during the bear market of 2000 and 2001 rapidly. However, once the market turns in 2002, the realized losses tend to stall, possibly because there are less losers in the portfolios of mutual funds. In the years 2003 and 2004 the cumulative realized gains increase only moderately although the market experiences a large upwards movement. Assuming that mutual fund managers are invested in the markets, this might 
be an indicator that the fund managers believe in a bull market and let their profits run. In 2005 we have a clearly observable increase in the average realized gains which is also reflected in the sum of realized gains and losses.

\subsection{Extent of the Disposition Effect Among Mutual Fund Managers}

In this section, we analyze the disposition effect in the whole panel database. This is achieved by taking the unrealized gains, unrealized losses, realized gains, and realized losses for all dates and each fund and calculating $P G R, P L R$, and the disposition effect measure (DEM) for each fund. The results after taking the average of this $D E M$ across all funds are figured in Table $2^{9}$

Table 2: Average $P G R, P L R$ and $D E M$ across all equally weighted mutual funds on USD and share basis.

\begin{tabular}{rrrr}
\hline USD basis & $1993-2005$ & $1993-1999$ & $2000-2005$ \\
\hline Number of Funds & 2248 & 1484 & 2130 \\
PGR & 0.310 & 0.339 & 0.323 \\
PLR & 0.229 & 0.225 & 0.237 \\
DEM & 0.082 & 0.114 & 0.087 \\
& & & \\
t-statistic & 23.85 & 23.11 & 22.81 \\
\hline Share basis & & & \\
\hline Number of Funds & 2248 & 1484 & 2130 \\
PGR & 0.350 & 0.331 & 0.366 \\
PLR & 0.318 & 0.289 & 0.331 \\
DEM & 0.032 & 0.042 & 0.034 \\
& & & \\
t-statistic & 30.33 & 23.04 & 31.53 \\
\hline
\end{tabular}

The table shows the proportion of gains realized, the proportion of losses realized, and its difference across the whole sample period and two subperiods on USD as well as share basis. PGR, PLR, and DEM are calculated for each fund and the average across all funds is displayed. The t-statistics test the hypothesis that the differences of $D E M$ are equal to zero.

The histogram of $D E M$ on a USD basis across the mutual funds in our sample is displayed in Figure 2. This figure shows a high dispersion of the disposition effect measure among mutual fund

\footnotetext{
${ }^{9}$ In this approach we assume that the disposition effect is independent across mutual funds.
} 
managers. Most mutual fund managers appear to exhibit a $D E M$ between 0 and 0.5 . However, not all mutual fund managers are subject to the tendency to hold losing stocks longer than winning stocks. The average $D E M$ across all mutual funds on a USD basis is 0.082 with a t-statistic of 23.85 (compare Table 2) 10 This contradicts the findings of Cici (2005) with his result of the disposition effect of -0.035 (t-statistic: -14.56). Our results, however, are in line with Da Silva Rosa, To, and Walter (2006) who find an average value of 0.0559 (t-statistic: 5.63) for their data of UK managed funds, which is of similar order of magnitude as our results. Furthermore, finding a positive disposition effect is in line with Frazzini (2006), Odean (1998), and Barber, Lee, Liu, and Odean (2007). To test our results for stability, we divide our entire sample into subsamples covering the time frames 1993-1999 and 2000-2005. For the two subsamples we can confirm our previous results (compare Table 2), providing evidence for their stability. The number of funds in the sample strongly increases during the technology boom period at the end of 1999 and the beginning of 2000. On a USD basis, the results for our subperiods indicate a higher disposition effect during 1993-1999 and a lower disposition effect in the more volatile market environment from 2000-2005. During the first subperiod we have a higher $P G R$ and lower $P L R$ than during the second. With the market being in an upwards trend from 1993 to 1999, fund managers appear to hold on to their losing stocks longer, hoping for a turnaround in the generally favorable market conditions. In an effort to test the stability of our results we repeat the analysis on a number of shares basis. Table 2 reveals that the averages of $P G R$ and $P L R$ are comparable to the analysis on a USD basis and the $D E M$ of 0.032 continues to be significant. The results for the subperiods are also in line with the results using the USD basis ${ }^{11}$ Thus, the evidence for a disposition effect among mutual fund managers is strong. Previous research by Odean (1998) obtains a $D E M$ of 0.21 with a t-statistic of 19. Barber, Lee, Liu, and Odean (2007) find a significant value of 0.0708 for all investors in the Taiwan Stock Exchange from 1995 to 1999. Given these results we conclude that

\footnotetext{
${ }^{10}$ Twenty-three mutual funds are excluded because of computational reasons such as not having a sale during their reporting period or selling shares for which the purchase price is not known.

${ }^{11}$ It exists a higher disposition effect from 1993-1999 than in the second subperiod.
} 
there is a disposition effect among mutual fund managers, but it is smaller than the one found for private investors. While the analysis this far calculates the $D E M$ for each mutual fund and then takes the average across mutual funds, we perform a stability test with a different specification. For this test we calculate $D E M$ by pooling all positions of all mutual funds together and calculate a $D E M$ for the whole industry. This treats the whole sample as if there were only one large mutual fund at each point in time. However, the results are consistent, giving us still a significant DEM measure 12

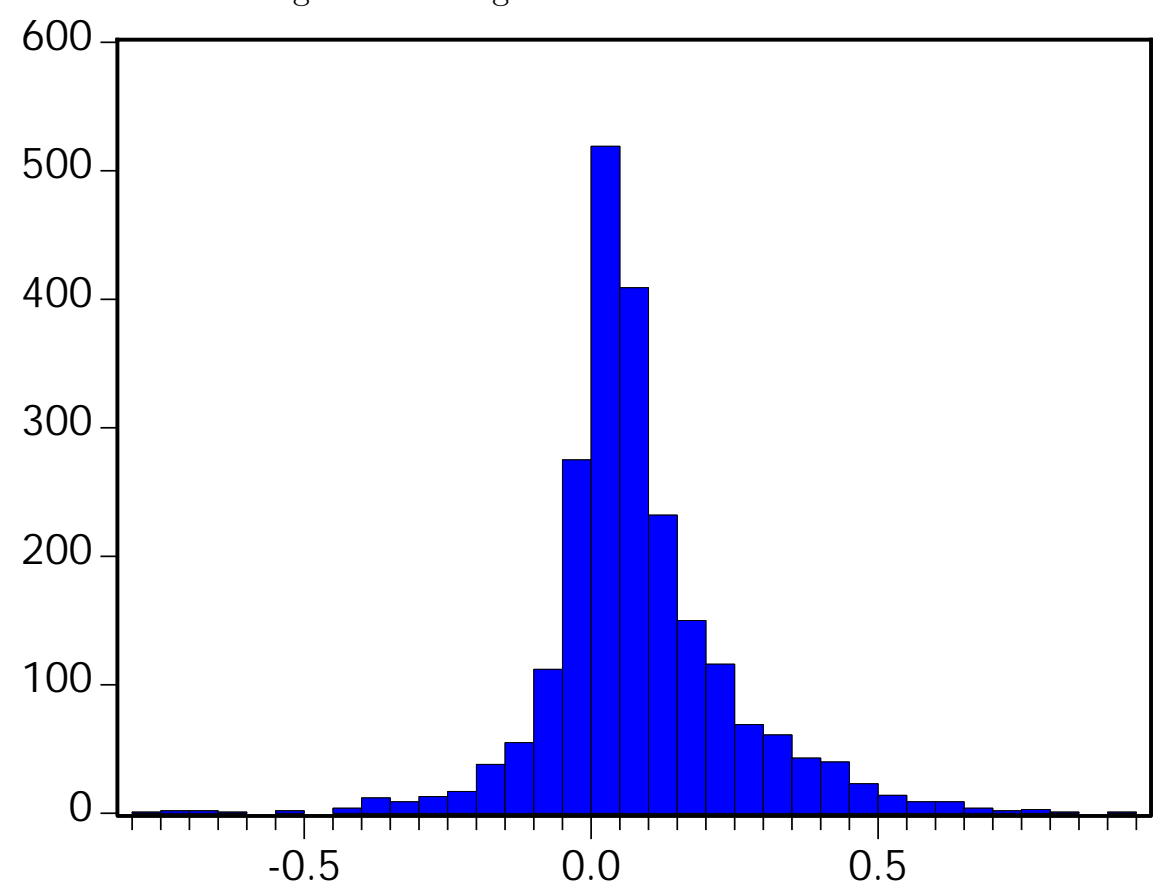

The figure shows the frequency of $D E M$ on USD basis across all mutual funds and the whole period with a median of 0.056 and a mean of 0.082 .

\footnotetext{
${ }^{12}$ In this approach $P G R, P L R$, and $D E M$ are calculated by aggregating paper gains, paper losses, realized gains, and realized losses across all dates and mutual funds on a number of shares basis. This corresponds to the basic approach for the calculation of the disposition effect chosen by Odean (1998). Using this approach, we obtain a relativ low disposition effect of 0.016 , but we can still reject the null hypothesis at the $1 \%$ significance level (tstatistic of 41.79). This value is in line with results by Frazzini (2006) as well as Da Silva Rosa, To, and Walter (2006) (values of 0.031 and 0.0012 with t-statistics of 43.6 and 28.7, respectively) for professional investors, but is significantly lower than the values obtained by Odean (1998) for private investors (value of 0.050 with a t-statistic of 34.98). Thus, the disposition effect appears to be more dominant among private investors.
} 
Table 3: Average $P G R, P L R$, and $D E M$ across all equally weighted mutual funds on USD basis from 1993-2005

\begin{tabular}{rrrr}
\hline USD basis & Jan.-Dec. & Jan.-Nov. & Dec. \\
\hline PGR & 0.310 & 0.305 & 0.291 \\
PLR & 0.229 & 0.224 & 0.209 \\
DEM & 0.082 & 0.082 & 0.081 \\
& & & \\
t-statistic & 23.85 & 22.63 & 18.87 \\
\hline
\end{tabular}

The table shows the proportion of gains realized, the proportion of losses realized, and the $D E M$ across the whole sample period on a USD basis. PGR, PLR, and DEM are calculated for each fund and the average across all funds is displayed for the whole year, for January to November, and for December. The t-statistics test the hypothesis that the $D E M$ is equal to zero.

Figure 3 shows the evolution of the disposition effect across time, where the disposition effect is calculated as the mean $D E M$ across all mutual funds reporting their holdings at a specific date. We see that the largest peaks are during strong market movements. On March 19th, 2000, the disposition effect is particularly weak. At this date the $P L R$ dominates the $P G R$. The largest up peak is observed on September 19th, 2001. It is possible that this spike is a result of September 11th, 2001, when most funds sold their remaining winning shares to realize their gains because they expected a continued bear market.

Finally, we analyze tax motivated selling activities at year end. Possibly the regulatory environment has a significant influence on the behavioral anomalies exhibited by mutual fund managers. Odean (1998) performs a similar analysis for private investors and finds a smaller disposition effect in December when compared to the rest of the year. Cici (2005) finds a decline in the average disposition effect in the last quarter. This contradicts the results of Da Silva Rosa, To, and Walter (2006), who find a higher disposition effect in March, the British financial year end, for UK managed funds. In contrast to Odean (1998) and Cici (2005), their results do not give evidence for tax motivated selling activity at year end. Table 3 shows that our results do not confirm the hypothesis of tax motivated selling behavior either. Mutual fund managers exhibit a constant 
Figure 3: DEM from 1993-2005 on USD basis.

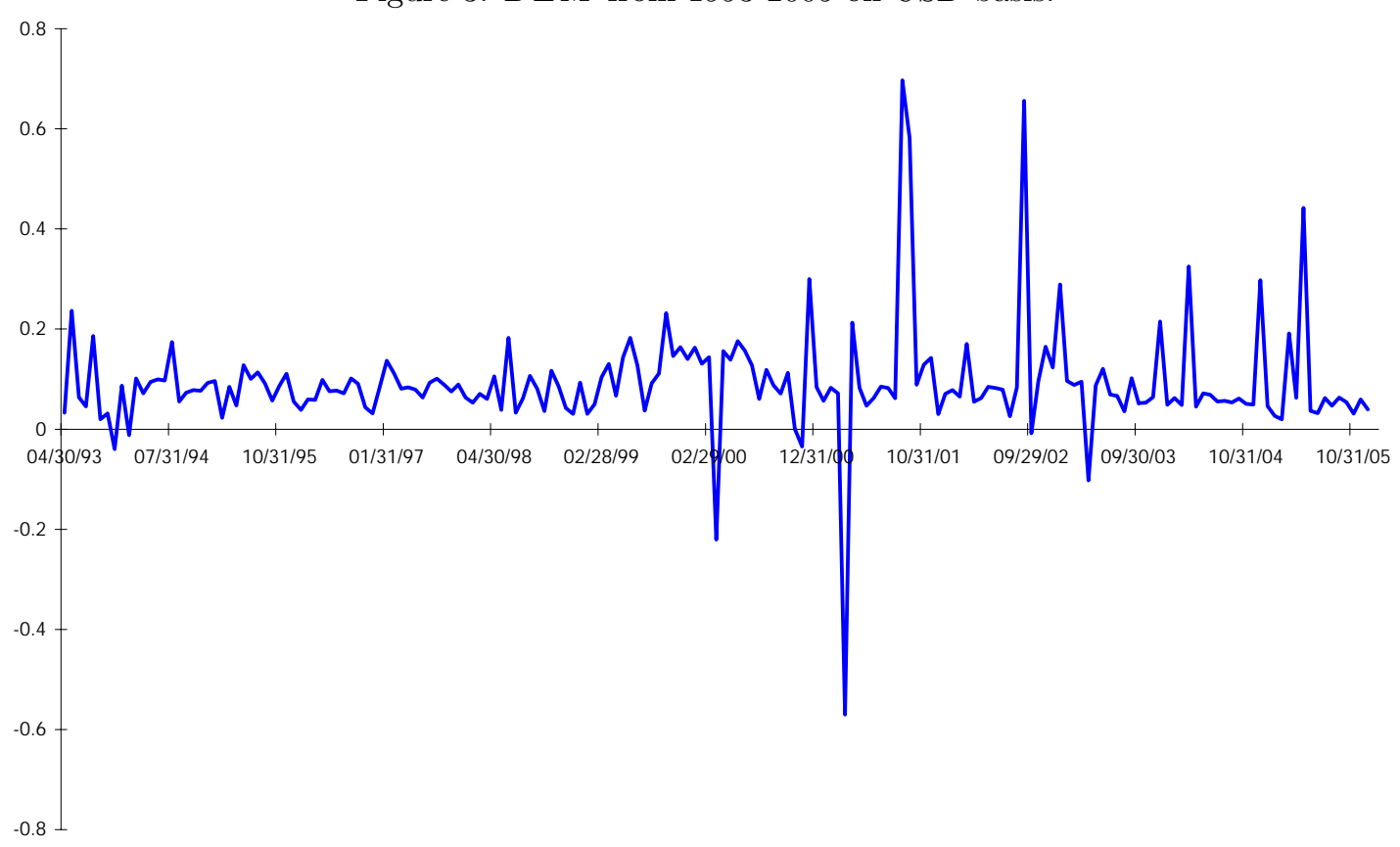

This figure shows the evolution of $D E M$. At each reporting date $D E M$ is calculated for each fund and then averaged across mutual funds.

disposition effect during the whole year. However, we find that $P G R$ and $P L R$ are on average smaller in December and a small decline of the DEM is in line with Odean (1998) and Cici (2005). Over all, fund managers sell a smaller proportion of their stocks in December than during the rest of the year.

\subsection{Investment Decisions of Fund Managers}

The previous sections established that there is a high dispersion among the disposition effects exhibited by mutual fund managers. This section analysis if this dispersion of the disposition effect across mutual fund managers is linked to differences in investment styles. To analyze if mutual fund managers with different $D E M$ levels follow different investment strategies, we analyze the characteristics of the stocks they invest in. In particular, we study the value-weighted mean trade volume, market capitalization, dividend return, book-to-market ratio, price-earnings ratio, mean 
return, volatility of returns, beta, and sharpe ratio of the equities held by mutual funds. These stock charecteristics are calculated for each stock in our sample. The respective figure for the mututal funds are obtained by taking value-weighted averages of the single stock figures. The mean return, volatility of returns, and the beta are obtained using daily data of the last three months before the respective reporting date. The volatility and the mean return are annualized using a 250 day convention. The beta is calculated with the S\&P500 as market index.

We report summary statistics of the equity characteristics for ten mutual fund subsamples formed on the basis of the disposition effect (i.e., a fund's $D E M$ ) in Table 4 . Decile 1 contains the mutual funds with the lowest and decile 10 the ones with the highest DEM. A fund can enter this statistic only once. If the database contains more than one report for a mutual fund, we calculate the mean $D E M$ and the mean equity characteristics across time for this fund and classify it into one of the 10 deciles according to this average.

The results reveal that mutual fund managers with a lower $D E M$ invest in different assets than the ones with a higher difference. It appears that mutual funds with a higher $D E M$ invest in equities with a lower average trade volume (e.g., 4.10 billions USD for the lowest and 3.16 billions USD for the highest decile) and a lower market capitalization (e.g., 38.26 billions USD for the lowest and 27.93 billions USD for the highest decile). Thus, mutual fund managers with higher disposition effect try to achieve a higher outperformance of their benchmark by investing in smaller stocks. Possibly they are convinced to find undervalued stocks in the small cap sector more easily. The difference between the highest and lowest decile is significant (t-statistics of 6.53 and 8.31 for trade volume and market capitalization, respectively).

We observe that the average dividend yield of the assets held by a mutual fund is the lowest for the mutual funds in the highest decile (0.0144 in lowest and 0.0102 in highest decile). This difference is statistically significant (3.67). Thus, mutual fund managers with high $D E M$ prefer 


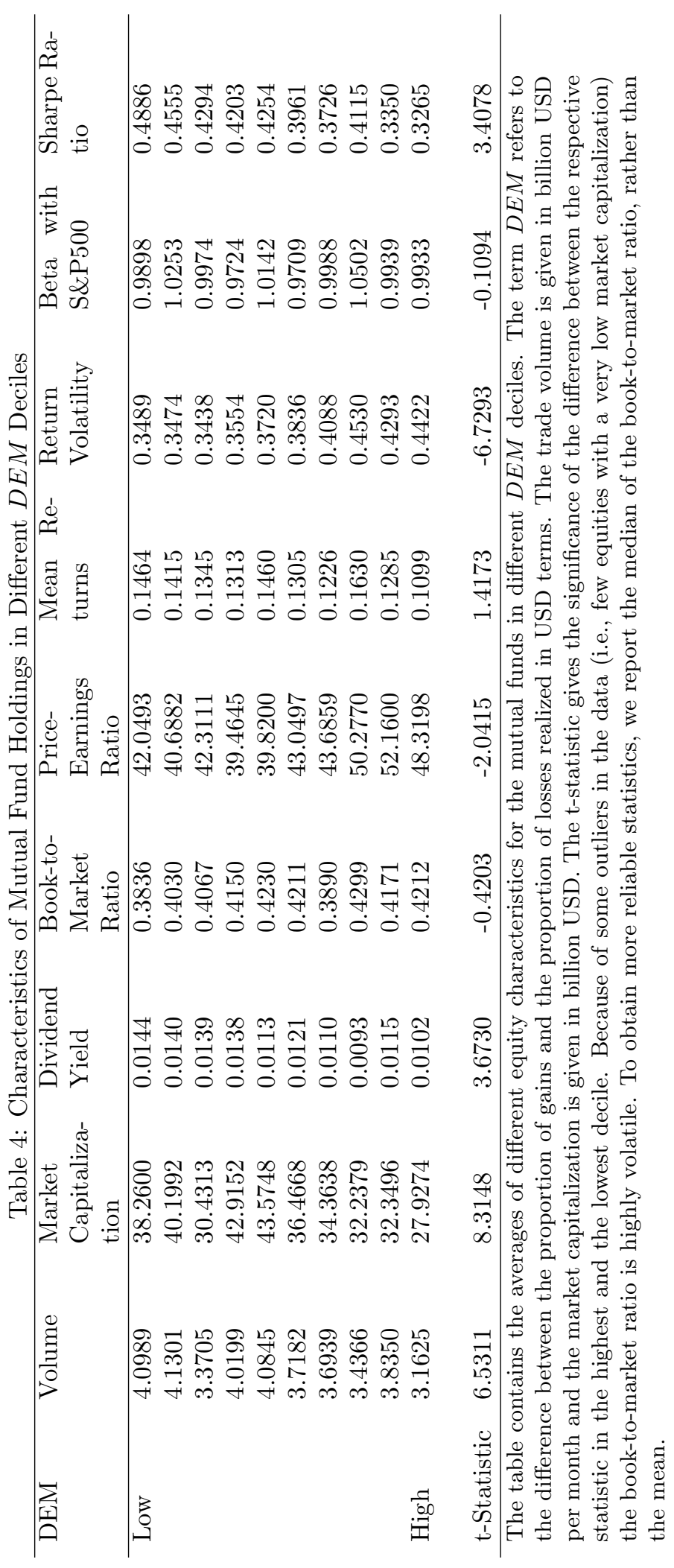


Figure 4: Average Sharpe Ratio in DEM Deciles

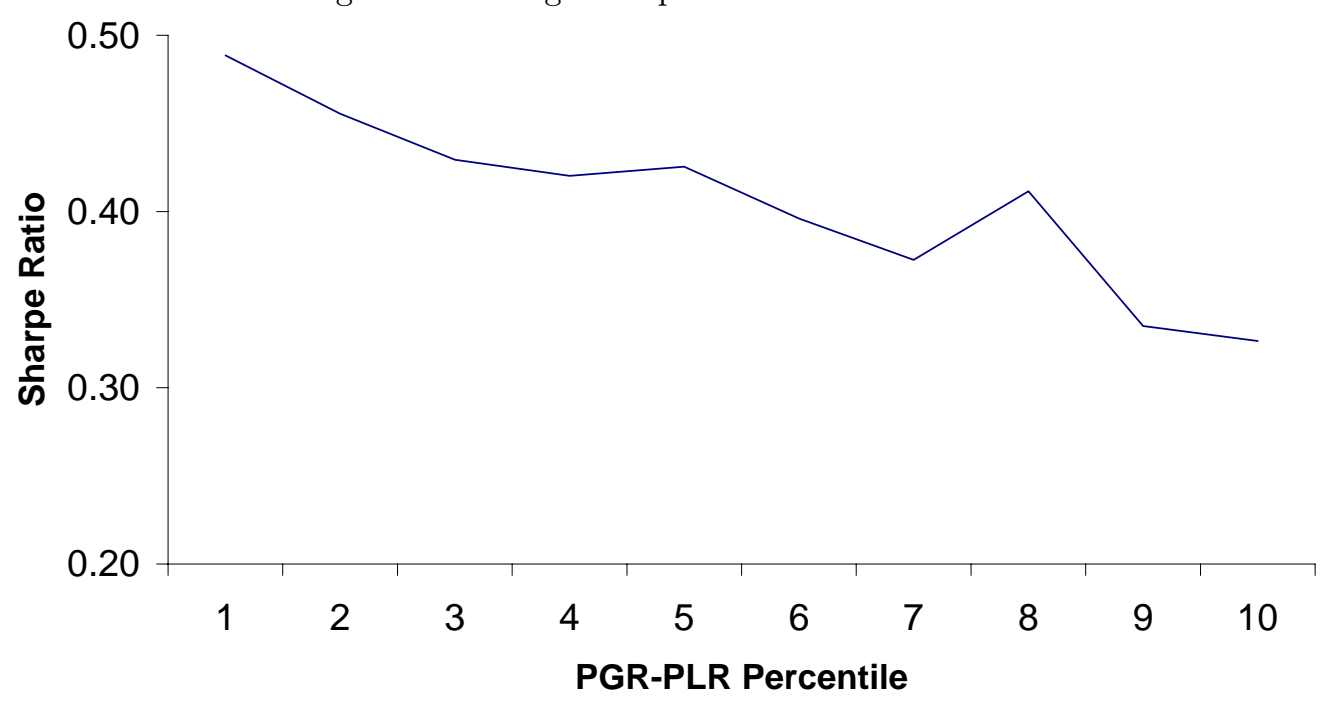

The figure shows the average sharpe ratios for mutual funds classified into deciles according to the disposition effect. Funds in decile 1 have the lowest and in decile 10 the highest disposition effect.

capital gains over dividend flows in their objective to achieve a good performance. The mean book-to-market ratio is highly erratic across equities. This is the reason why we report the median of this measure, which is less vulnerable to the book-to-market ratio outliers in our sample. The median of the book-to-market ratio gives weak evidence for an increase of this measure as the $D E M$ increases. Thus, mutual fund managers with a higher $D E M$ appear to invest in cheaper equities as measured by the price per USD book value. However, the difference between the bookto-market ratio in the highest and lowest decile is not significantly different from zero (t-statistic of -0.42$)$ and this result has to be treated with care. Furthermore, the statistically significant results for the price-earnings ratios do not support this finding. For the managers in the highest three $D E M$ deciles the highest price-earnings ratios are measured $(50.28,52.16$, and 48.32$)$. In the lowest decile, the holdings of the funds have an average price-earnings ratio of 42.05 , which is significantly lower (t-statistic of -2.04) than the ratio in the highest decile. Therefore, managers with a lower disposition effect invest in cheaper stocks as measured by the price-earnings ratio. 
Analyzing the past performance of the equities held by the mutual funds, we find that the mean return of the stocks in the first decile (0.1464) is higher than the one in the tenth decile (0.1099). This is not surprising given that a higher $D E M$ reflects the tendency to realize gains faster than losses, suggesting that winners are sold too early and losers too late. More interesting is the fact that mutual funds in the low decile hold equities that exhibited a lower risk in the past three months (volatility of 0.3489 compared to 0.4422 in the high decile). Thus, mutual fund managers who are less subject to the disposition effect tend to invest in equities with lower idiosyncratic risk. The level of systematic risk (i.e., beta) across the disposition effect deciles shows no clear pattern (e.g., values of 0.9898 and 0.9933 for the lowest and the highest decile, respectively). However, given that mutual funds are not completely diversified, the higher idiosyncratic risk of the assets of fund managers with low ability indicates that their overall portfolios are also more risky. The higher average past returns and the lower risk level of the holdings of mutual funds in the low $D E M$ decile result in a higher average sharpe ratio for fund managers with a lower disposition effect (compare Figure 4). The difference between the low decile (value of 0.4886) and the high decile (0.3265) is significant at the $1 \%$ level (t-statistic of 3.41).

In summary, we find that there is a link between the disposition effect exhibited by mutual fund managers and their investment styles. Therefore, the disposition effect has material effects on the portfolio held by a mutual fund. Fund managers with a lower disposition effect are found to invest on average in larger equities with a higher trade volume. The valuation of stocks as summarized in the price-earnings ratio gives evidence that managers with a lower $D E M$ prefer to hold cheaper stocks. Furthermore, a lower disposition effect goes along with an investment in equities with a higher past performance, lower idiosyncratic risk, and higher risk adjusted performance. These results motivate our focus on the link between the performance of mutual funds and the disposition effect in Section 6 . 


\section{Determinants of the Disposition Effect}

\subsection{Impact of Fund Characteristics on the Realization of Gains and Losses}

Having found that differences in the disposition effect measure go along with differences in investment styles, this section analyzes the link between mutual fund characteristics and the disposition effect. This objective is achieved by regressing the $P G R$, the $P L R$, and the $D E M$ on a range of mutual fund characteristics. The characteristics of the mutual funds are the percentage of total assets invested in equities, the expense ratio, the turnover ratio, the logarithm of the total net asset value of the fund, the annual return, the lifetime of the fund in months, the manager experience (measured by the number of months the manager is in charge of the fund), and the mutual fund strategy (aggressive growth, growth, growth \& income, small cap, and others).

For the link between the mutual fund characteristics in the regression and the disposition effect measure we have a range of hypothesis. Gil-Bazo and Ruiz-Verd (2005) develop a theoretical model featuring fund managers with high and low ability. They find that mutual fund managers with low ability charge higher fees to their investors. Thus, if the disposition effect is a sign for ability a higher DEM should go along with larger fees. A higher turnover is found by Carhart (1997) to reduce the abnormal fund performance. If the $D E M$ really measures the ability of fund managers, then a higher turnover should be associated with a lower DEM. Further hypotheses are that larger mutual funds are expected to be managed by better fund managers therefore have a lower $D E M$. The annual fund return is expected to have a negative impact on the $D E M$ measure since mutual fund managers might be more willing to realize losses once the past performance has been well. We expect that a longer lifetime and a higher manager experience go along with a higher ability of the managers of a mutual fund, which might be linked to a lower disposition effect. This hypothesis is derived from Dhar and Zhu (2002), who analyze data of 50,000 individual investors from 1991-1996. They find evidence for the existence of the disposition effect, but show that more 
experienced and better informed investors do not hold losing stocks longer than winning stocks.

To test these hypotheses we perform a regression using the following specification:

$$
\begin{aligned}
P G R-P L R & =\alpha^{\text {Diff }}+\delta_{1}^{\text {Diff }} \cdot \% \text { Equity }+\delta_{2}^{\text {Diff }} \cdot \text { Expenses }+\delta_{3}^{\text {Diff }} \cdot \text { Turnover } \\
& +\delta_{4}^{\text {Diff }} \cdot \ln (T N A)+\delta_{5}^{\text {Diff }} \cdot \text { Return }+\delta_{6}^{\text {Diff }} \cdot \text { Launch } \\
& +\delta_{7}^{\text {Diff }} \cdot \text { Experience }+\delta_{8}^{\text {Diff }} \cdot D_{\text {AggressiveGrowth }}+\delta_{9}^{\text {Diff }} \cdot \text { D }_{\text {Growth }} \\
& +\delta_{10}^{\text {Diff }} \cdot D_{\text {Growth }+ \text { Income }}+\delta_{11}^{\text {Diff }} \cdot D_{\text {SmallCap }}+\epsilon^{\text {Diff }},
\end{aligned}
$$

where Equity is the percentage of fund assets invested in stocks, Expenses is the expense ratio, Turnover is the funds' turnover ratio, $\ln (T N A)$ is the logarithm of the total value of fund holdings, Return is the fund return during the last year, Launch is the number of months since the fund launch, Experience is the number of months since the present fund manager took control, and $D$ indicates dummy variables for the style classification of the mutual funds. We orthogonalized the manager experience since it has comparably high correlations with other explanatory variables (e.g., 0.258 and 0.297 with $\ln (T N A)$ and the elapsed time since launch, respectively). The other explanatory variables exhibit moderate correlations with an average of -0.02 and only four correlations exceeding an absolute value of 0.1 . The highest correlation of -0.33 is found for the logarithm of TNA and the expense ratio and the lowest correlation of 0.41 is found for the logarithm of TNA and the mutual fund age. Given correlations among the explanatory variables are generally low and we use a large dataset, multicollinearity does not pose an issue.

Since the dataset used in the regression covers 2,271 mutual funds over 13 years, we need to control for the econometric particularities of panel data. Parks (1967) is the first to use a generalized least squares (GLS) methodology for the analysis of panel data. Beck and Katz (1995) extend this model and derive panel-corrected standard errors (PCSE) for the significance tests of 
estimated parameters. These panel-corrected standard errors control for contemporaneous correlation and heteroscedasticity across the categories of the panel as well as autocorrelation within the time series. By applying the methodology by Beck and Katz (1995), we can correct in our regressions for contemporaneous correlation and heteroscedasticity among mutual fund returns as well as for autocorrelation within the returns of each fund. This approach is implemented by using ordinary least squares (OLS) to estimate the regression parameters. However, the significance of the estimated parameters is tested with panel-corrected standard errors. We calculate the sampling variability of the OLS estimates by the square roots of the diagonal terms of

$$
\operatorname{Cov}\left(\hat{\delta}_{i}\right)=\left(\mathbf{X}^{\prime} \mathbf{X}\right)^{-1} \mathbf{X}^{\prime} \hat{\mathbf{\Omega}} \mathbf{X}\left(\mathbf{X}^{\prime} \mathbf{X}\right)^{-1}
$$

where $\mathbf{X}$ is a vector of the exogenous variables and $\hat{\boldsymbol{\Omega}}$ the covariance matrix of the errors. The difference comes from the estimation of $\hat{\boldsymbol{\Omega}}$. Since we have a contemporaneous correlation in the panel data we need to correct the standard errors. For this we calculate $\hat{\boldsymbol{\Omega}}$ by

$$
\hat{\mathbf{\Omega}}=\frac{\left(E^{\prime} E\right)}{T} \otimes I,
$$

where $E$ is the $T \times N$ matrix of the OLS residuals with $N$ the number of units and $\otimes$ the Kronecker product. The results of the regression with PCSE are reported in Table 5

The explanatory power of specification 22 for the disposition effect (i.e., DEM) is limited $\left(R^{2}\right.$ of 0.008). However, some of the parameters are significantly different from zero and indicate that there are significant links between the disposition effect and the institutional characteristics of a mutual fund. The expense ratio has a parameter of 1.5941 , which is significant at the $1 \%$ level. Thus, mutual fund managers with a larger disposition effect tend to charge their customers higher fees. This is in accordance with Gil-Bazo and Ruiz-Verd (2005) if we interpret a larger disposition 


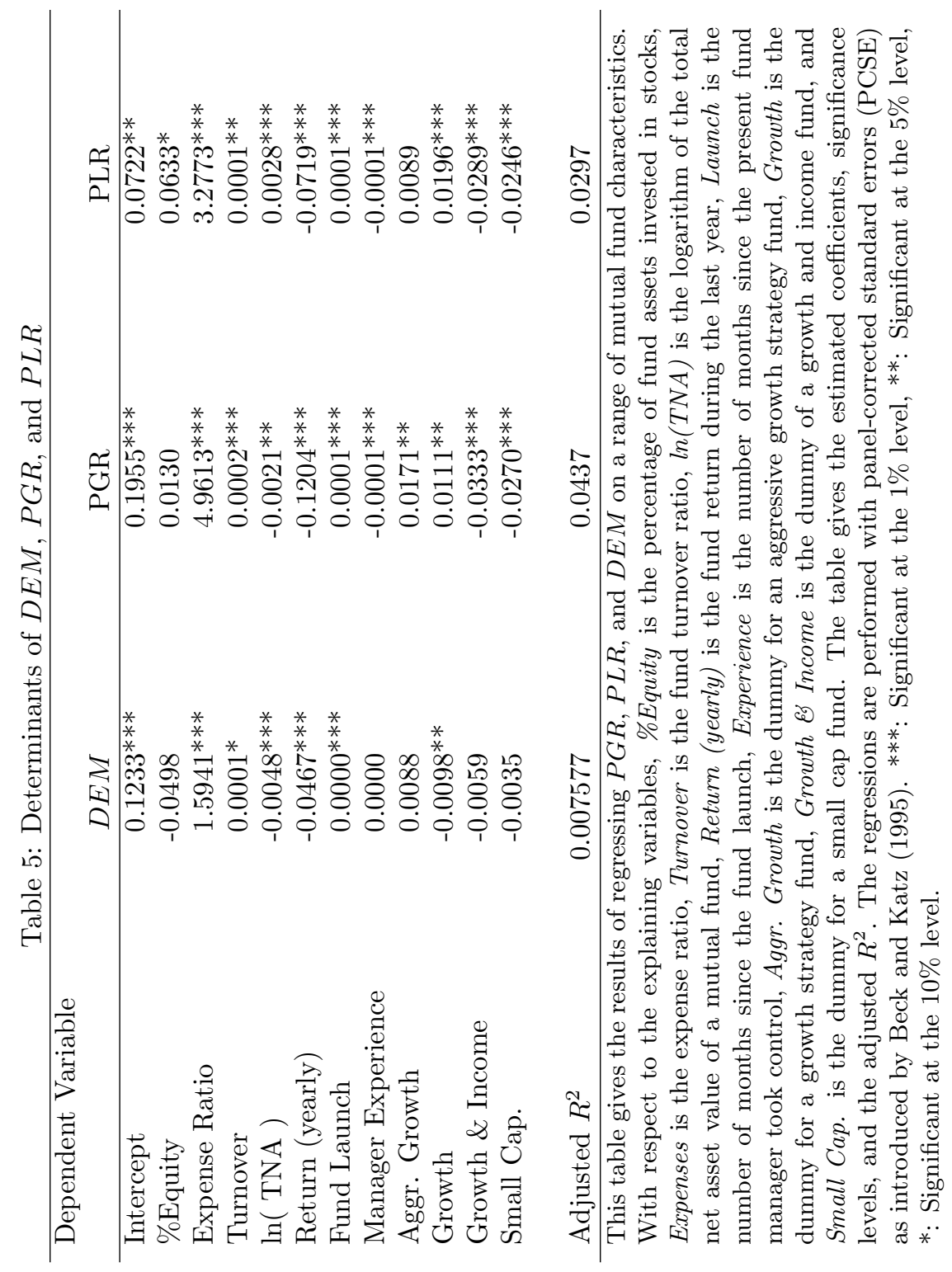


effect as a sign of a lower ability. The turnover of the mutual fund is also positively linked to the disposition effect (parameter of 0.0001 significant at the $5 \%$ level). This shows that an increase in the trading activity often involves that winning stocks are sold earlier than losing stocks. The increase in the selling activities of funds with a higher turnover appears to be stronger among winning stocks than among losing stocks. This tendency to hold losers comparably long could be a reason for the worse performance of mutual funds with a higher turnover as is found by Carhart (1997). A larger mutual fund as measured by the logarithm of total net assets is found to exhibit on average a lower disposition effect (parameter of -0.0048 is significant at the $1 \%$ level). Another interesting finding is the fact that a higher one-year return goes along with a lower disposition effect (parameter of -0.0467 is significant at the 1\% level). Wermers (2003) and Frazzini (2006) support this result. Wermers (2003) shows that mutual fund managers of underperforming funds are less willing to sell their losing stocks. Frazzini (2006) sorts mutual funds into quintiles by their previous year's return and shows that badly performing funds have a higher disposition effect than well performing funds. Apparently, mutual fund managers with a better past track record are less reluctant to realize losses. The age of the fund has a positive impact on the disposition effect (significant parameter of 0.00003). In economic terms this effect is significant as well: An increase of the lifetime of a mutual fund by 5 years results on average in an increase of the disposition effect (measured as $D E M$ ) by 0.002 or $2.4 \%$. Apparently in the course of the lifetime of a fund there is no development of mechanisms to reduce behavioral anomalies, such as the disposition effect. Therefore, we find little evidence for an institutional evolution of mutual funds over time. The manager experience has no significant impact on $D E M$, which is an indication that experience does not help mutual fund managers to overcome the disposition effect. Among the strategy dummies only the one for the growth strategy is significantly different from zero (parameter of 0.0098 is significant at the $5 \%$ level). Thus, managers of growth funds exhibit on average a smaller disposition effect in their investment decisions. In a further regression (results are not reported in 
tables), we add dummies for open-end funds and funds targeted to institutional investors to the explaining variables. This raises the $R^{2}$ to 0.0117 . While the parameter for institutional investors is not significantly different from zero, the parameter of -0.0321 for open-end funds is significant at the $1 \%$ level. This result indicates that funds which are open to new investors have a lower $D E M$ measure and appear to realize gains and losses more simultaneously. The results are robust in the subperiods $1 / 1993-12 / 1999$ and $1 / 2000-12 / 2005$.

While the $D E M$ only indicates how likely the realization of gains is relative to the realization of losses, a separate analysis of $P G R$ and $P L R$ can give new information on the absolute readiness of fund managers to realize gains and losses (i.e., the probability to realize gains and losses). For such an analysis we regress the $P G R$ and the $P L R$ of mutual funds separately on the explaining variables:

$$
\begin{aligned}
P G R & =\alpha^{P G R}+\delta_{1}^{P G R} \cdot \% \text { Equity }+\delta_{2}^{P G R} \cdot \text { Expenses }+\delta_{3}^{P G R} \cdot \text { Turnover }+\delta_{4}^{P G R} \cdot \ln (\text { TNA) } \\
& +\delta_{5}^{P G R} \cdot \text { Return }+\delta_{6}^{P G R} \cdot \text { Launch }+\delta_{7}^{P G R} \cdot \text { Experience }+\delta_{8}^{P G R} \cdot D_{\text {AggressiveGrowth }} \\
& +\delta_{9}^{P G R} \cdot D_{\text {Growth }}+\delta_{10}^{P G R} \cdot D_{\text {Growth }+ \text { Income }}+\delta_{11}^{P G R} \cdot D_{\text {SmallCap }}+\epsilon^{P G R}
\end{aligned}
$$

$$
\begin{aligned}
P L R & =\alpha^{P L R}+\delta_{1}^{P L R} \cdot \% \text { Equity }+\delta_{2}^{P L R} \cdot \text { Expenses }+\delta_{3}^{P L R} \cdot \text { Turnover }+\delta_{4}^{P L R} \cdot \ln (T N A) \\
& +\delta_{5}^{P L R} \cdot \text { Return }+\delta_{6}^{P L R} \cdot \text { Launch }+\delta_{7}^{P L R} \cdot \text { Experience }+\delta_{8}^{P L R} \cdot D_{\text {AggressiveGrowth }} \\
& +\delta_{9}^{P L R} \cdot D_{\text {Growth }}+\delta_{10}^{P L R} \cdot D_{\text {Growth }+ \text { Income }}+\delta_{11}^{P L R} \cdot D_{\text {SmallCap }}+\epsilon^{P L R} .
\end{aligned}
$$

The explanatory power of these regressions is larger than for the $D E M$, but still moderate. For the regression with $P G R$ and $P L R$ adjusted $R^{2}$ of 0.0437 and 0.0297 , respectively, are obtained 
(compare Table 5). The expense ratio has a positive parameter for the proportion of gains (4.961 with t-statistic of 14.33 ) and losses (3.2773 with t-statistic of 11.58) realized, indicating that mutual funds with higher fees tend to realize gains and losses faster. Since we control for turnover, this effect is not linked to a higher overall trading activity of these mutual funds. This behavior could be a cause for the decrease in abnormal performance for mutual funds with higher fees as it is found by Carhart (1997). Larger mutual funds are found to have a lower $D E M$. Analyzing the $P G R$ and the PLR measures, we find that larger funds have a lower PGR (parameter of -0.0021 significant at the $5 \%$ level) and a higher PLR (parameter of 0.0028 significant at the $5 \%$ level). The effect of the $P G R$ and $P L R$ has opposite signs, indicating a particularly clear effect of the fund size on the extent of the disposition effect. The fund managers of larger funds appear to be more willing to realize losses while they tend to let profits run. The fund performance during the past year has significantly negative parameters for PGR (-0.0719) and PLR (-0.1204). Thus, a good past performance does not encourage fund managers to sell losers and realize paper profits. Apparently, these managers are reluctant to change their successful portfolio. The fund launch variable has positive parameters for both measures (0.0001 for $P G R$ and 0.0001 for $P L R$, both significantly different from zero at the $1 \%$ level), indicating that funds with a longer history tend to realize a larger proportion of their gains and losses in each reporting period. Possibly this is a sign of fund management rules which are in place in older funds as a result of an investment process evolution over time. The manager experience has an effect in the opposite direction. The longer a mutual fund is managed by a manager, the lower is the percentage of realized gains (parameter of - 0.0001 significant at the $1 \%$ level) and losses (parameter of -0.0001 significant at the $1 \%$ level). Such a behavior would be reasonable if more experienced mutual fund managers believe in a momentum effect for winners and a revearsal effect for losers. Although the results in this section provide various insights in the links between the disposition effect and fund characteristics, the results have to be interpreted with care given the low $R^{2}$ (0.03 and 0.04 for $P G R$ and $P L R$, respectively). 


\subsection{Impact of the Economic Environment on the Realization of Gains and Losses}

Having studied the effect of the characteristics of mutual funds on the disposition effect, this section studies the effect of the macroeconomic environment on the disposition effect exhibited by mutual funds. This analysis is motivated by the assumption that mutual fund managers and their behavior is influenced by the economic environment.

We use five economic indicators which are assumed to track the development of the US economy. One of the most important variables is the growth of the gross national product (GNP). Another important indicator for the state of an economy is inflation. Higher inflation is likely to be followed by rising interest rates and can serve as an early indicator for higher cost of borrowing. The state of the capital market is summarized by the mean and volatility of the SBSP500 return. Using the University of Michigan Consumer Sentiment index the effects of rather subjective sentiments on the fund management are included in the analysis. The economic variables are obtained on a monthly basis, except for the growth of the gross national product, which is obtained on a quarterly basis, but interpolated linearly to obtain monthly figures. We estimate the parameters of the following specification to study the link between the disposition effect and the economic environment:

$$
\begin{aligned}
D E M & =\alpha^{E c o n}+\delta_{1}^{E c o n} \cdot \text { Inflation }+\delta_{2}^{E c o n} \cdot G N P+\delta_{3}^{E c o n} \cdot \mu_{S \& P}+\delta_{4}^{E c o n} \cdot \sigma_{S \& P} \\
& +\delta_{5}^{E c o n} \cdot \text { Sentiment }+\epsilon^{E c o n}
\end{aligned}
$$

where Inflation is the US inflation, GNP is the growth of the gross national product, $\mu_{S \& P}$ is the mean return of the $\mathrm{S} \& \mathrm{P} 500$, and $\sigma_{S \& P}$ is the volatility of the S\&P500 ${ }^{13}$ The correlation

${ }^{13}$ Since the correlation between mutual fund characteristics and the economic environment is low, we do not include these variables as control variables. 
between the economic variables is in general moderate and we do not need to undertake any precautions against multicollinearity 14 Consistent with the previous section, the regressions are performed with panel-corrected standard errors (PCSE) as introduced by Beck and Katz (1995).

The economic environment is not able to explain a large proportion of the variation in the $D E M$ (adjusted $R^{2}$ of 0.0064$){ }^{15}$ The impact of the consumer confidence on the $D E M$ is significantly positive (parameter of 0.0004 is significant at the $1 \%$ level). Therefore, an increased consumer sentiment results in a higher disposition effect among mutual fund managers. With a fluctuation of the consumer confidence between 74.2 and 112.0 during the time frame of our analysis, the expected impact of the consumer confidence on the disposition effect can be economically significant. The parameter of 4.0447 for the volatility of the S\&P500 is also significantly different from zero (at the $1 \%$ level). It indicates that an increased risk at the capital market leads on average to a higher disposition effect. A separate regression of $P G R$ and $P L R$ on the economic factors returns significant parameters of 5.9243 and 1.7415 , respectively, for volatility. Therefore, although the disposition effect appears to be more pronounced (i.e., $D E M$ is higher) in more risky capital markets, the direction of the reaction of the managers is symmetric for positions with gains and losses. The parameters for the other factors are not significantly different from zero.

In summary, this section finds a significant influence of the economic environment on the disposition effect exhibited by mutual fund managers. However, the regressions deliver only a low $R^{2}$ and, therefore, the extent of the influence of the economic environment on the disposition effect is limited.

\footnotetext{
${ }^{14}$ Correlations are between -0.29 for the volatility of the S\&P500 and the GNP growth and 0.25 for the mean returns of the S\&P500 and consumer confidence. Only for the correlation between the volatility and the mean return of the S\&P500 we obtain a larger correlation figure of -0.43 . However, since we work with a very large dataset, multicollinearity does not pose a problem.

${ }^{15}$ Results are not reported in tables for brevity.
} 


\section{Disposition Effect and Performance}

\subsection{Alphas of Mutual Funds and Disposition Effect}

In the previous sections we found that there is strong evidence for the disposition effect. Furthermore, we found a direct link between the disposition effect and a range of equity characteristics, fund characteristics, and the economic environment. However, if the disposition effect does not translate into an adverse impact on mutual fund performance, then it might not be evidence for irrational behavior. Instead, the fact that losers are held longer than winners could be the result of a successful reversal strategy in which fund managers wait for losers to recover. Therefore, this section analyzes the link between the disposition effect and fund performance.

For this reason we use the Carhart (1997) 4-factor model to determine the alphas of mutual funds. To be more specific, we estimate the parameters of the following regression for each mutual fund:

$$
r_{i, t}=\alpha_{i}+\gamma_{i, 1} \cdot R M R F_{t}+\gamma_{i, 2} \cdot S M B_{t}+\gamma_{i, 3} \cdot H M L_{t}+\gamma_{i, 4} \cdot M O M_{t}+\epsilon_{i, t},
$$

where $r_{i, t}$ is the return of fund $i$ at time $t, R M R F$ the market excess return, $S M B$ the SmallMinus-Big factor, $H M L$ the High-Minus-Low factor, and $M O M$ a momentum factor for the stock returns. We use the CRSP mutual fund database to calculate mutual fund returns. Since daily mutual fund returns are available only since 2001, we have to use monthly return data from CRSP since $1993{ }^{16}$ We group the mutual funds in the sample in deciles according to their alpha. To study the link between the disposition effect and alpha, we calculate the average USD-based disposition effect for the mutual funds in each alpha decile.

Table 6 contains the results of this methodology. Each decile contains between 239 and 243 observations. The alphas of the mutual funds are on average between -0.0150 and 0.0045 . The

\footnotetext{
${ }^{16}$ However, repeating the analysis with the available daily data confirms our results.
} 
Table 6: Link between Alpha and the DEM Using a the Carhart 4-Factor Model

\begin{tabular}{r|rrr|rrr|r}
\hline & \multicolumn{3}{|c}{ DEM } & & \multicolumn{3}{c}{ Alpha } \\
& Mean & Median & Stdv & Mean & Median & Stdv & of Observations \\
\hline 1 & 0.1294 & 0.1235 & 0.2744 & -0.0150 & -0.0135 & 0.0061 & 239 \\
2 & 0.1012 & 0.0921 & 0.2540 & -0.0096 & -0.0095 & 0.0007 & 239 \\
3 & 0.0843 & 0.0701 & 0.2587 & -0.0078 & -0.0077 & 0.0004 & 239 \\
4 & 0.0639 & 0.0600 & 0.2499 & -0.0066 & -0.0065 & 0.0003 & 239 \\
5 & 0.0944 & 0.0723 & 0.2302 & -0.0056 & -0.0055 & 0.0003 & 239 \\
6 & 0.0568 & 0.0500 & 0.2458 & -0.0046 & -0.0046 & 0.0003 & 239 \\
7 & 0.0590 & 0.0422 & 0.2203 & -0.0036 & -0.0036 & 0.0003 & 239 \\
8 & 0.0353 & 0.0273 & 0.2232 & -0.0026 & -0.0026 & 0.0003 & 239 \\
9 & 0.0332 & 0.0294 & 0.2200 & -0.0014 & -0.0014 & 0.0004 & 239 \\
10 & 0.0548 & 0.0240 & 0.2370 & 0.0045 & 0.0013 & 0.0115 & 243 \\
\hline
\end{tabular}

The table gives the results of the $D E M$ ranked according to the alphas. We use the Carhart (1997) 4-factor model to determine the alphas of the mutual funds. These alphas are grouped in deciles. Decile 1 contains the funds with the lowest and decile 10 the ones with the highest alpha.

average $D E M$ of the mutual funds in each decile decreases as the generated alpha increases. For the worst performing decile a disposition effect of 0.1294 is measured, while it decreases to 0.0548 for the highest alpha decile. The measured disposition effect is subject to a large standard deviation in each decile. For the worst performing funds a standard deviation of the disposition effect of 0.2744 is measured. A standard t-test for differences between the disposition effect in deciles 1 and 10 returns a value of 3.194 . Therefore, there appears to be a link between the excess performance and the disposition effect exhibited by fund managers 17

In a further analysis we regress the alphas of the 4-factor model on the disposition effect of the respective mutual fund. The parameter obtained for the $D E M$ is -0.0023 (t-statistic of 4.266) 18 This indicates that a larger $D E M$ is linked to a lower abnormal performance. With the average disposition effect measure running at 0.082 (compare Table 2), this causes an expected performance

\footnotetext{
${ }^{17}$ The disposition effect reflects a behavioral pattern which is similar to momentum and reversal investment. Possibly, the 4-factor model erroneously captures the impact of the disposition effect on alpha in the momentum component. Therefore, we repeat the analysis with the 3-factor model by Fama and French (1993), which does not have a momentum component and obtain similar results. The disposition effect is the largest (value of 0.1477 ) for fund managers with the lowest alpha (value of -0.0167). Although in general an increase in alpha goes along with a lower disposition effect, the link between the disposition effect and the performance is not linear.

${ }^{18}$ The intercept of the regression is -0.0050 and has a t-statistic of 36.863. Cici (2005) finds in his regression a lower value of -0.0110 (t-statistic: -2.60$)$.
} 
loss of $-0.02 \% \sqrt{19}$ For the mutual funds in the worst alpha decile in Table 6 , the disposition effect causes an expected alpha reduction of $0.03 \%$ (i.e., $0.1294 *-0.0023$ ). Considering that the mean alpha is $-1.50 \%$, the disposition effect appears to be only of minor importance in its explanation. This impression is further strengthened by the $R^{2}$ of 0.0076 obtained in this regression, indicating that the disposition effect is able to explain less than $1 \%$ of the variation in alpha across mutual funds.

Another measure frequently used in performance measurement is the information ratio (IR). This measure is defined as

$$
I R_{i}=\frac{\alpha_{i}}{\sigma\left(\epsilon_{i}\right)}
$$

where $\sigma\left(\epsilon_{i}\right)$ is the volatility of the residual in the 4-Factor model in Carhart (1997). This measure is a performance figure which puts the obtained $\alpha$ in perspective to its volatility. Thus, the $I R$ corrects for the risk level and leverage chosen by a mutual fund manager, making it a performance measure which is better suited for a comparisson of different mutual funds.

As in the previous analysis, the funds are sorted according to their information ratio and then allocated to 10 deciles (compare Table 7). The largest average disposition effect of 0.09434 is found in the worst performing decile 1 (information ratio of -0.47172) and the third lowest disposition effect of 0.05773 in decile 10 (information ratio of 0.04502). Again we find an indication that there is a link between the disposition effect and performance. However, the disposition effect measure does not decrease monotonically from decile 1 to 10 . Instead it behaves more erratically than for the pure alphas (compare Table 6), exhibiting the second highest disposition effect figure in decile

\footnotetext{
${ }^{19}$ Regressing the Fama-French alpha of the fund on the disposition effect returns a significant parameter of -0.0029 (t-statistic: -5.145) for the disposition effect figure. Cici (2005) finds a value of -0.0219 (t-statistic: -4.15) for the 3 -factor model. With the average disposition effect measure of 0.082 , our result amounts to an average performance impact of $-0.02 \%$. The impact of the disposition effect on the mutual fund performance is weak from an economic perspective. The low $R^{2}$ of 0.0110 lends further support to this claim. Therefore, our results are robust to the usage of momentum in our risk factor regressions.
} 
Table 7: Link between Information Ratios and the DEM Using a the Carhart 4-Factor Model

\begin{tabular}{r|rrr|rrr|r}
\hline & \multicolumn{3}{|c}{ DEM } & \multicolumn{5}{c}{ Information Ratio } \\
& Mean & Median & Stdv & Mean & Median & Stdv & Number of Obs. \\
\hline 1 & 0.0943 & 0.0799 & 0.2508 & -0.5342 & -0.4717 & 0.2892 & 239 \\
2 & 0.0699 & 0.0515 & 0.2167 & -0.3555 & -0.3535 & 0.0213 & 239 \\
3 & 0.0867 & 0.0603 & 0.2415 & -0.2967 & -0.2951 & 0.0120 & 239 \\
4 & 0.0629 & 0.0378 & 0.2435 & -0.2585 & -0.2573 & 0.0113 & 239 \\
5 & 0.0907 & 0.0780 & 0.2182 & -0.2229 & -0.2225 & 0.0096 & 239 \\
6 & 0.0720 & 0.0705 & 0.2469 & -0.1905 & -0.1899 & 0.0090 & 239 \\
7 & 0.0570 & 0.0369 & 0.2679 & -0.1612 & -0.1616 & 0.0095 & 239 \\
8 & 0.0537 & 0.0390 & 0.2467 & -0.1190 & -0.1206 & 0.0145 & 239 \\
9 & 0.0674 & 0.0500 & 0.2542 & -0.0592 & -0.0595 & 0.0194 & 239 \\
10 & 0.0577 & 0.0245 & 0.2422 & 0.0775 & 0.0450 & 0.1024 & 243 \\
\hline
\end{tabular}

The table gives the results of the $D E M$ ranked according to the information ratios. We use the Carhart (1997) 4-factor model to determine the alphas of the mutual funds. These alphas are grouped into deciles. Decile 1 contains the funds with the lowest and decile 10 the ones with the highest alpha.

5. Therefore, the link between risk adjusted excess performance and disposition effect appears to be weaker. Regressing the obtained information ratios on the disposition effect figure, a parameter of -0.0237 is obtained. This indicates that an increase in the disposition effect figure goes along with a decrease in performance. In contrast to the regression of the alphas on the disposition effect, the parameter for risk-adjusted excess performance (i.e., IR) is not significantly different from zero (t-statistic of -1.5117) and the $R^{2}$ is at only 0.0010 . These facts add to the evidence that the impact of the disposition effect on mutual fund performance is limited.

\subsection{Link Between the Timing of Transactions and the Disposition Effect}

This section analysis the relationship between the disposition effect and performance in more detail. In this analysis we improve the timing of fund managers artificially by holding losing stocks shorter and winning stocks longer than the fund actually does. We do this to test if a change of the dates of sales can decrease the disposition effect and increase the realized profits. This would be the case if fund managers stick to stocks with a downwards trend too long and sell upwards trending stocks too early. If it turns out that this modified timing has no effect on performance, then the disposition effect (i.e., sticking to losing stocks longer than to winning stocks) is of more interest 
from a psychological point of view and less so from a performance and market rationality point of view.

Table 8: Average $P G R, P L R$ and $D E M$ across all equally weighted mutual funds on USD and share basis for different buy and sell time shifts.

\begin{tabular}{rrrr}
\hline USD basis & $+/-1$ month & $+/-3$ months & $+/-6$ months \\
\hline PGR & 0.313 & 0.324 & 0.336 \\
PLR & 0.220 & 0.212 & 0.216 \\
DEM & 0.092 & 0.112 & 0.120 \\
& & & \\
t-statistic & 26.30 & 31.89 & 33.90 \\
\hline Share basis & & & \\
\hline PGR & 0.348 & 0.346 & 0.349 \\
PLR & 0.316 & 0.295 & 0.298 \\
DEM & 0.031 & 0.051 & 0.050 \\
& & & \\
t-statistic & 27.00 & 42.63 & 41.00 \\
\hline
\end{tabular}

The table shows the proportion of gains realized, the proportion of losses realized, and the $D E M$ across the whole sample period on USD and share basis. Winning stocks are expected to be sold 1, 3, or 6 months later and losing stocks the corresponding period earlier. $P G R, P L R$, and $D E M$ are calculated for each fund and the average across all funds is displayed. The t-statistics test the hypothesis that the $D E M$ is equal to zero.

In our analysis we test the effect of holding winning shares 1,3 , and 6 months longer than the mutual fund actually does and losing stocks 1, 3, and 6 months shorter. Our approach is naive in the sense that it does not take into account the effect of a different timing on subsequent investment decisions and their financing ${ }^{20}$ At the new selling date we check if the sale is a realized gain or a realized loss and calculate the new $D E M$. The results of the average $D E M$ across all mutual funds for all three time shifts are displayed in Table 8 . The results for $+/-1$ month are nearly the same as in the base case (compare Table 2). For a time shift of 3 months, gains (losses) are realized more (less) frequently on a USD basis as in the base case ( $P G R$ increases from 0.310 to 0.324 once

\footnotetext{
${ }^{20}$ The sale proceedings of a stock that is held longer in our approach might have been originally used to buy another stock. By postponing the sale, this new stock might have to be financed by a credit, causing costs we do not consider. However, since this approach is solely taken to analyze the disposition effect, this simplification is reasonable.
} 
a shift of 3 months is performed on sales and PLR decreases from 0.229 to 0.212 ). The longer the time shift the greater the disposition effect (on a USD basis the DEM increases from 0.082 for the base case to $0.092,0.112$, and 0.120 for shifts of 1,3 , and 6 months, respectively). For the share basis the $P G R$ is nearly the same over all 3 time shifts. For 3 and 6 months the $P L R$ declines so that the disposition effect becomes greater. All results are statistically significant at the $1 \%$ level. By forcing the the mutual fund to hold winners longer and losers shorter, we intend to correct for the behavioral bias described by the disposition effect. However, our manipulation results in the contrary and the DEM actually increases. Therefore, although the mutual fund managers would behave more rational, the $D E M$ indicates the contrary. In light of these results we conclude that the $D E M$ might be an indicator for the extent of a behavioral anomaly, but it is not necessarily linked to a suboptimal fund management and mutual fund performance.

Table 9: Realized gains and realized losses in bn USD for different sale times.

\begin{tabular}{|c|c|c|c|}
\hline 1993-2005 & $+/-1$ month & $+/-3$ months & $+/-6$ months \\
\hline Realized gains & 6,238 & 6,235 & 6,175 \\
\hline Realized losses & $-3,222$ & $-3,210$ & $-3,220$ \\
\hline Realized gains+realized losses & 3,016 & 3,025 & 2,955 \\
\hline
\end{tabular}

The table summarizes the realized gains, losses, and their sum across the whole sample period. Winning stocks are expected to be sold 1, 3, or 6 months later and losing stocks the corresponding period earlier.

Table 9 shows the realized gains and losses in USD over the whole sample period for time shifts of 1, 3, and 6 months. For the 1-month time shift the realized gains increase about $3.5 \%$ and the losses decrease about $1.4 \%$ so that the overall realized net profit increases by over $\$ 200$ billions. The increase in profits is mainly driven by the higher gains. Thus, our methodology can improve the timing of sales for winning stocks, but it has a smaller impact on the losses of the unprofitable positions. From a performance point of view our approach has a larger effect on the winning positions than for the losing positions. For the other time shifts we also measure an increase in the overall profits (profits rise from $\$ 6,026$ to $\$ 6,235$ and $\$ 6,175$ billions for time shifts 
of 3 and 6 months, respectively) and little changes for the losses (losses drop from $\$ 3,267$ to $\$ 3,209$ and $\$ 3,220$ billions for time shifts of 3 and 6 months, respectively). Not surprisingly, these results indicate that fund managers do not have a perfect timing for their sales. The extent of the changes in profitability is relatively small when compared to the changes of the disposition effect figure 21

The analysis this far established that an improvement in timing leads to slightly higher net profits and an increase in the disposition effect measure. However, if the $D E M$ were a good indicator for behavioral irrationality, we would have expected a decrease in the $D E M$. Thus, the $D E M$ does not appear to be a clean measure for behavioral irrationality and the hypothesized links between $D E M$ and mutual fund performance cannot be supported by empirical evidence.

Table 10: Average $P G R, P L R$ and $D E M$ across all equally weighted mutual funds on USD basis for the standard case and additional sales.

\begin{tabular}{lrrrr}
\hline USD basis & standard & sales $+50 \%$ & sales $+70 \%$ & sales $+80 \%$ \\
\hline Number of Funds & 2248 & 2248 & 2248 & 2248 \\
PGR & 0.310 & 0.315 & 0.316 & 0.316 \\
PLR & 0.229 & 0.295 & 0.310 & 0.316 \\
DEM & 0.082 & 0.020 & 0.006 & -0.001 \\
& & & & \\
t-statistic & 24 & 5.63 & 1.54 & -0.18 \\
\hline
\end{tabular}

The table shows the proportion of gains realized, the proportion of losses realized, and its difference across the whole sample period on USD basis. PGR, PLR, and DEM are calculated for each fund and the average across all funds is displayed. The t-statistics test the hypothesis that the $D E M$ is equal to zero.

Since all three time steps do not result in a reduction of the disposition effect and an increase in realized profits, we adopt a new approach. At each point where a sale takes place in a mutual fund and we have a realized loss, we increase the amount of shares sold by $50 \%, 70 \%$, and $80 \%$. The sales can not be greater than the remaining shares in the portfolio. After each additional sale we adjust the remaining amount of shares in the portfolio for the following reporting dates.

\footnotetext{
${ }^{21}$ Our results could be biased because we assume all transactions take place at the reporting period although in reality they take place between the two reporting dates. To control for this possible mismatch, we repeat the calculations with prices one month before the reporting date. However, the results are essentially unchanged.
} 
This approach artificially increases the activity of mutual fund managers and results in a higher willingness to sell losers. If this approach significantly reduces the disposition effect, but does not significantly increase profits, we add further evidence to the hypothesis that the disposition effect has only a limited impact on performance (i.e., might not be irrational). Furthermore, it would indicate that the measure used for the disposition effect might pick up a general lack of trading activity.

The results for a disposition effect measure on a USD basis are displayed in Table 10 . In the first column we have the standard case from Table 2 , in the second to fourth the additional sale of $50 \%, 70 \%$, and $80 \%$ of shares. The results of the three approaches for generating additional sales are very different. Our goal to reduce the disposition effect is achieved by the increase of the PLR, while the PGR remains stable, as expected ${ }^{22}$ For the $50 \%$ additional sales the disposition effect drops to 0.20 and is significant with a t-statistic of 5.63. For the last two cases the $D E M$ drops further to 0.006 and becomes even negative with -0.001 for $80 \%$ additional sales. In both cases it is not significantly different from zero. Compared to the standard case in Section 4.2 the disposition effect (value of 0.082 ) drops significantly in all cases. While the improved timing earlier in this section had an adverse effect on the $D E M$, the increased activity actually reduces the $D E M$.

The results for the impact of the three sales modifications on profits are given in Table 11 . The realized gains decrease (from $\$ 6,026$ to $\$ 5,927, \$ 5,894$, and $\$ 5,878$ billions for the $50 \%, 70 \%$ and $80 \%$ additional sales, respectively) and the realized losses increase (from $\$ 3,267$ to $\$ 3,482$, $\$ 3,518$, and $\$ 3,533$ billions for $50 \%, 70 \%$, and $80 \%$ additional sales, respectively) ${ }^{23}$ This results in a reduction of the realized net profits from $\$ 2,759$ to $\$ 2,445, \$ 2,376$, and $\$ 2,345$ billions for additional sales $50 \%, 70 \%$, and $80 \%$, respectively. The net unrealized profits in the portfolio of

\footnotetext{
${ }^{22}$ Minor changes in $P G R$ can be attributed to the fact that changes in sales of losing stocks have an impact on subsequent holdings and, therefore, on PGR if the price increases and the position becomes a gain.

${ }^{23}$ The reason for the decline of the realized gains is that the amount of shares that are sold with a gain sometimes is smaller than in the standard case due to the fact that there are less shares left in the portfolio that can be sold.
} 
Table 11: Realized gains, realized losses, unrealized gains, and unrealized losses for standard case and additional sales in bn USD.

\begin{tabular}{lrrrr}
\hline 1993-2005 & standard & sales $+50 \%$ & sales $+70 \%$ & sales $+80 \%$ \\
\hline Realized gains & 6,026 & 5,927 & 5,894 & 5,878 \\
Realized losses & $-3,267$ & $-3,482$ & $-3,518$ & $-3,533$ \\
Realized gains+realized losses & 2,759 & 2,445 & 2,376 & 2,345 \\
\hline Unrealized gains at reporting end & 708 & 686 & 683 & 682 \\
Unrealized losses at reporting end & -136 & -95 & -90 & -88 \\
\hline Total gains + losses & 3,331 & 3,036 & 2,969 & 2,939 \\
\hline
\end{tabular}

The table summarizes the realized gains, losses, and their sum, as well as the unrealized gains and losses in the portfolio of the mutual funds at their last reporting date across the whole sample period.

the mutual funds also decline. Summing unrealized and realized profits together, we find that the additional sales lead to a decrease of net profits from $\$ 3,331$ billions in the standard case to $\$ 3,036$ billions for the case with $50 \%$ higher sales, $\$ 2,969$ billions for $70 \%$, and $\$ 2,939$ billions for $80 \%$ higher sales. The empirical evidence shows clearly that an increase in the sales at each point in time, leads to a decrease of the fund performance. However, the increase of the trading activity lead to a large reduction of the $D E M$. Therefore, the results do not support the hypothesis that a higher disposition effect leads to a lower mutual fund performance.

In summary, this section analyzes the link between the timing of sales, the measured disposition effect, and the mutual fund performance. First, sales of winning stocks are postponed to a later point in time and the sale of losers are executed earlier. Therefore, the asymmetry in the timing of the sales of winners and losers should be reduced, resulting in a reduction of the $D E M$. Interestingly, this manipulation of the data increases the disposition effect and illustrates that the $D E M$ is not a clean measure for the asymmetric timing of the realization of gains and losses. The realized total profits increase through the time shifts, indicating that the expected negative impact of the disposition effect on performance might not be strong. Having found that the disposition effect is not measuring asymmetric timing, we test whether it is more a measure for a lack of activity in selling losing stocks. In fact, forcing mutual funds to increase the sales of losing stocks reduces the 
disposition effect while it also reduces the total profits. This effect further illustrates that a higher disposition effect measure does not necessarily induce a worse mutual fund performance.

\section{Conclusion}

The disposition effect refers to the observation that investors are reluctant to realize losses, thus holding losing stocks longer than winning stocks. Using mutual fund holdings data from 1993-2005, we obtain evidence for the existence of the disposition effect for mutual fund managers. Finding that even professional investment managers are subject to this behavioral pattern, we analyze the relation between stock characteristics, mutual fund characteristics, the economic environment, the performance of mutual funds, and the disposition effect.

We find that mutual funds with a low disposition effect invest in larger stocks with more favorable risk-return characteristics. Analyzing the explanatory power of fund characteristics and the economic environment for the disposition effect, we find that the explanatory power is small. The regression of the disposition effect on the fund characteristics shows that the expense ratio, the turnover, the one-year return, the launch date, and the style (growth funds) are significant parameters. Consumer confidence and the volatility of the S\&P500 also have a significant impact on the disposition effect.

Finally, we study the relationship between the disposition effect and performance. We calculate alphas of mutual funds using a Carhart (1997) 4-factor model to find that the disposition effect decreases only weakly with increasing alpha. In a further analysis we reduce the disposition effect in the actions of fund managers by modifying transaction sizes. Since the disposition effect measure and the overall profit of the mutual funds decrease at the same time, we obtain further evidence that the disposition effect does not necessarily correspond to a negative impact on fund performance. Therefore, the disposition effect appears to be more of a mild behavioral twist than a performance-erroding behavioral irrationality. 


\section{References}

Barber, B. M., Y.-T. Lee, Y.-J. Liu, and T. Odean (2007): "Is the Aggregate Investor Reluctant to Realize Losses? Evidence from Taiwan," European Financial Management, 13(3), $423-447$.

Barber, B. M., and T. Odean (1999): "The Courage of Misguided Convictions," Financial Analysts Journal, 55(6), 41-55.

Beck, N., And J. N. Katz (1995): "What to Do (and Not to Do) with Time-Series Crosssection Data," American Political Science Review, 89(3), 634-647.

Brown, Philip, Chappel, Nick, D. Rosa, Ray, Walter, and Terry (2006): "The Reach of the Disposition Effect: Large Sample Evidence Across Investor Classes," International Review of Finance, 6(1-2), 43-78.

Carhart, M. (1997): "On Persistence in Mutual Fund Performance," Journal of Finance, 52(1), $57-82$.

CICI, G. (2005): "The Relation of the Disposition Effect to Mutual Fund Trades and Performance," Working paper, Mason School of Business, College of William and Mary.

Da Silva Rosa, R., H. M. To, and T. Walter (2006): "Tests of the Disposition Effect amongst UK Managed Funds," Working paper, University of Western Australia.

Dhar, R., and N. Zhu (2002): "Up Close and Personal: An Individual Level Analysis of the Disposition Effect," Yale ICF Working paper No. 02-20.

Fama, E. F., and K. R. French (1993): "Common Risk Factors in the Returns on Stocks and Bonds," Journal of Financial Economics, 33(1), 3-56.

Frazzini, A. (2006): "The Disposition Effect and Underreaction to News," The Journal of Finance, 61(4), 2017-2046. 
Frino, A., D. Johnstone, And H. Zheng (2004): "The Propensity for Local Traders in Futures Markets to Ride Losses: Evidence of Irrational or Rational Behavior?," Journal of Banking $\&$ Finance, 28(2), 353-372.

Gil-Bazo, J., And P. Ruiz-Verd (2005): "When Cheaper is Better: Fee Determination in the Market for Equity Mutual Funds," Working paper, Universidad Carlos III de Madrid.

Grinblatt, M., And B. Han (2005): "Prospect Theory, Mental Accounting, and Momentum," Journal of Financial Economics, 78(2), 311-339.

Grinblatt, M., and M. KeloharJu (2001): "What Makes Investors Trade?," Journal of Finance, 56(2), 589-616.

Kahneman, D., And A. Tversky (1979): "Prospect Theory: An Analysis of Decision under Risk," Econometrica, 47(2), 263-292.

Krishnan, R., And D. M. Booker (2002): "Investors' Use of Analysts' Recommendations," Behavioral Research in Accounting, 14, 129-156.

Locke, P. R., And S. C. MAnn (2005): "Professional Trader Discipline and Trade Disposition," Journal of Financial Economics, 76(2), 401-444.

Odean, T. (1998): “Are Investors Reluctant to Realize Their Losses?,” Journal of Finance, 53(5), $1775-1798$.

Oehler, A., K. Heilmann, V. Lager, and M. Oberlander (2003): "Coexistence of Disposition Investors and Momentum Traders in Stock Markets: Experimental Evidence," Journal of International Financial Markets, Institutions and Money, 13(5), 503-524.

PARKs, R. W. (1967): "Efficient Estimation of a System of Regression Equations when Disturbances are Both Serially and Contemporaneously Correlated," Journal of the American Statistical Association, 62(318), 500-509. 
Shapira, Z., And I. Venezia (2001): "Patterns of Behavior of Professionally Managed and Independent Investors," Journal of Banking \& Finance, 25(8), 1573-1587.

Shefrin, H., and M. Statman (1985): "The Disposition to Sell Winners Too Early and Ride Losers Too Long: Theory and Evidence," Journal of Finance, 40(3), 777-791.

Shumway, T., And G. Wu (2005): "Does Disposition Drive Momentum?," Working paper, University of Michigan.

Weber, M., And C. F. Camerer (1998): "The Disposition Effect in Securities Trading: An Experimental Analysis," Journal of Economic Behavior \& Organization, 33(2), 167-184.

Wermers, R. (2000): "Mutual Fund Performance: An Empirical Decomposition into StockPicking Talent, Style, Transactions Costs, and Expenses," Journal of Finance, 55(4), 1655-1695.

_ (2003): "Is Money Really 'Smart'? New Evidence on the Relation Between Mutual Fund Flows, Manager Behavior, and Performance Persistence," Working paper, University of Maryland. 